\title{
APRESENTAÇÃO DOSSIÊ: PRÁTICAS E PROCESSOS SOCIOCULTURAIS NA AMAZÔNIA
}

\author{
Antonio Sardinha* \\ Universidade Federal do Amapá/UNIFAP
}

\author{
Marcos Vinícius de Freitas Reis ${ }^{* *}$ \\ Universidade Federal do Amapá/UNIFAP
}

\author{
Yuji Gushiken*** \\ Universidade Federal de Mato Grosso/UFMT
}
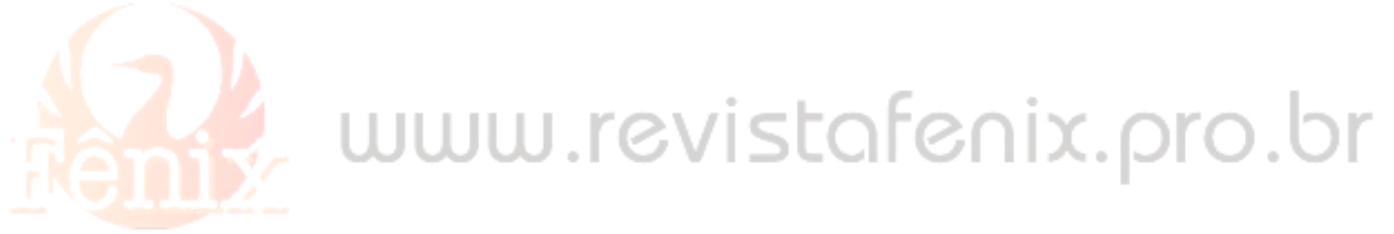

Professor da Universidade Federal do Amapá (Unifap). Atua na área de comunicação e estudos de cultura na interface com questões de gênero, sexualidade e direitos humanos. Integra como líder o Grupo de Pesquisa Estudos Interdisciplinares em Cultura e Políticas Públicas (CNPq/UNIFAP) e do Grupo de Pesquisa Mídia, política e democracia.

** Doutor em Sociologia pela Universidade Federal de São Carlos. Docente do Curso de Mestrado Acadêmico em História Social da UNIFAP. Docente do Curso de Mestrado Profissional Ensino de História UNIFAP. Docente do Curso de Graduação em Relações Internacionais e História da Universidade Federal do Amapá (UNIFAP). Docente da Especialização Estudos Culturais e Politicas Públicas. Editor da Revista Tempo Amazônico ligado a ANPUH AP. Líder do Centro de Estudos de Religião, Religiosidades e Politicas Públicas (CEPRES). Assessor da Secretaria de Educação do Estado do Amapá sobre a Base Nacional Comum Curricular (BNCC) no tocante ao Ensino Religioso. Coordenador do Observatório da Laicidade do Amapá. Assessor do Grupo de Trabalho da REPAM Sinodo do Amazônia.

*** Professor, pesquisador, um dos criadores e ex-coordenador (2016-2018) do Programa de PósGraduação Interdisciplinar (Mestrado e Doutorado) em Estudos de Cultura Contemporânea da Universidade Federal de Mato Grosso (UFMT). Vinculo atual no Departamento de Comunicação Social da Faculdade de Comunicação e Artes da Universidade Federal de Mato Grosso, em Cuiabá, Mato Grosso, Brasil. Doutor (2004) e mestre (1998) em Comunicação e Cultura pela Universidade Federal do Rio de Janeiro (UFRJ). Editor associado da Revista Internacional de Folkcomunicação (RIF) e membro do Conselho Consultivo da Revista Latinoamericana de Jornalismo (Âncora). Líder do Grupo de Pesquisa em Comunicação e Cidade (Citicom-UFMT/CNPq). Atualmente, desenvolve o projeto de pesquisa Comunicação e Cidade: Interfaces Interdisciplinares (Propeq-UFMT: 2016-2018) e o Laboratório de Jornalismo Cultural e Comunicação Organizacional em Ambiente de PósGraduação (Pós-Ciborg). 
O dossiê "Práticas e processos socioculturais na Amazônia" é uma iniciativa do Grupo de Pesquisa em Estudos Interdisciplinares em Cultura e Políticas Públicas da Universidade Federal do Amapá e do Grupo de Pesquisa em Comunicação e Cidade da Universidade Federal de Mato Grosso.

O objetivo da proposta foi apresentar resultados de investigação, no âmbito de programas de pós-graduação stricto sensu e de grupos de pesquisa, no país e no exterior, que se propõem a descrever, analisar e refletir sobre fenômenos, práticas e processos sociais que atravessam ou são atravessados pelo campo cultural. A proposta considera a apropriação de dispositivos e artefatos tecnológicos/comunicacionais, artísticos e literários em suas mais diversas linguagens para produção, circulação e reconhecimento de sentidos sobre e a partir da Amazônia.

A Amazônia, definida em distintos critérios, entre científicos e políticoadministrativos, compreende um território entre 5,1 milhões e 8,1 milhões de quilômetros quadrados, abrangendo territórios de oito países: Brasil, Bolívia, Colômbia, Equador, Guiana, Peru, Suriname e Venezuela.

Com aproximadamente 38,7 milhões de habitantes na chamada "Amazônia Maior", a região, caracterizadamente heterogênea, apresenta também, no âmbito continental, diferentes níveis de desenvolvimento econômico, distintas formações urbanas e múltiplas representações identitárias. As regiões de florestas equatoriais, embora constituam o imaginário recorrente sobre a Amazônia, precisam ser pensadas também em suas margens, terminações e periferias.

Trata-se de áreas ecossistêmicas de transição e contato da floresta amazônica com cerrados, chapadões e outras formações, subjetivadas ao longo do extenso território e atualizadas nas mais variadas paisagens culturais. Em território brasileiro, as amplas faixas de transição compreendem áreas de fricção e contato entre a Região Norte e as regiões Nordeste e Centro-Oeste, além de áreas de fronteira que, em âmbito sulamericano, produzem espaços de aproximações com culturas andinas e caribenhas.

O entendimento é o de que a Amazônia é um espaço privilegiado para observação de fenômenos, processos e práticas socioculturais em perspectiva interdisciplinar. Buscamos estimular o diálogo entre pesquisadores de distintas áreas do conhecimento, considerando as respectivas e potentes interfaces com o amplo campo cultural. 
O dossiê está marcado por uma abordagem interdisciplinar, incluindo contribuições das áreas de Ciências Sociais, Geografia, História, Filosofia e Comunicação. Os autores são pesquisadores com formação, trajetória acadêmica e/ou atuação em programas de pós-graduação marcados também pelo diálogo da interdisciplinaridade.

Destacamos também que a abordagem interdisciplinar vem assinada por pesquisadores com diversidade de origem (Pará, Amazonas, Paraná, Tocantins, Amapá, Maranhão e Rio de Janeiro), observando desde realidades muito particulares, que marcam o complexo e plural território amazônico, a amplos processos culturais constitutivos de fenômenos sociais característicos da região.

Parte substancial dos pesquisadores provém de programas de pós-graduação stricto sensu em instituições localizadas nos estados amazônicos. A nosso ver, este dado é relevante na medida em que atribui responsabilidade acadêmica e científica aos docentes em atividade na Amazônia. Trata-se de uma geração de docentes pesquisadores assumindo um lugar de fala acadêmico na produção de saberes sobre o território onde vivem, visando a construção de um campo científico na região.

É relevante também anotar que parte desta produção científica tem como origem a relação entre orientadores e orientandos, o que evidencia um primeiro processo de revisão interna da produção científica. Esta atitude traduz o esforço de docentes, no âmbito de grupos de pesquisa e de programas de pós-graduação, na formação de novas gerações de mestres e doutores.

As informações oriundas do conjunto de artigos evidenciam também uma prática em amadurecimento: a participação de pares da comunidade científica com mais experiência na produção de artigos, de modo a inscrever, desde o início da formação acadêmica, um esforço de revisão interna, necessariamente ponderada e autocrítica, da produção científica no que se refere à construção teórica e à organização de dados empíricos, num movimento autorreflexivo próprio do ambiente científico.

Se cada artigo tende a ser tornar um documento, através deles é possível observar a constituição e a busca pela consolidação de um sistema de fato nacional de pós-graduação, uma vez que o conjunto de textos indica o que cada autor faz de seu lugar de fala institucional: agregar, à função de ensino, a função de pesquisador (daí a categoria “ensino de pós-graduação"), malgrado as dificuldades políticas, econômicas e 
Disponível em: www.revistafenix.pro.br

administrativas no cotidiano dos espaços que se propõem a ser, concretamente, universitários.

Num momento em que a ciência, de modo geral, e as ciências sociais e humanas, em particular, tornam-se alvo de intenso combate, é necessário reafirmar que os distintos campos científicos devem ser fabulados como narrativas possíveis e relevantes no nosso modo de estar no mundo. Quando se trata de realidade amazônica e suas margens, esta é uma condição histórica e geográfica que faz adensar a responsabilidade e os desafios.

A característica deste dossiê é a reunião de um conjunto de textos que discutem como as questões culturais marcam, constituem e produzem o cotidiano amazônico. Ao contrário de uma imagem comum, as sociedades amazônicas se mostram complexas nas formas de organização econômica, política e social, constituídas por experiências comunitárias e paisagens particulares, evidenciadas pelo estudo de práticas e processos culturais.

O diálogo interinstitucional e interdisciplinar sinaliza esta importante tendência de produção científica sobre a Amazônia, hoje marcada por um movimento vital em busca da compreensão das dinâmicas da região. Ou seja, um movimento que compreende uma perspectiva de diálogo crítico entre saberes, situados desde uma periferia potencialmente produtiva para produção e circulação de conhecimentos que situam esta vasta região no cenário da pesquisa científica no país. 